\title{
Huez-Alpe d'Huez, Brandes-en-Oisans
}

Marie-Christine Bailly-Maître

URL : http://journals.openedition.org/adlfi/3407

ISSN : 2114-0502

Éditeur

Ministère de la culture

\section{Référence électronique}

Marie-Christine Bailly-Maître, «Huez-Alpe d'Huez, Brandes-en-Oisans », ADLFI. Archéologie de la France Informations [En ligne], Rhône-Alpes, mis en ligne le 01 mars 2009, consulté le 03 mai 2019. URL

http://journals.openedition.org/adlfi/3407

Ce document a été généré automatiquement le 3 mai 2019.

(c) Ministère de la Culture et de la Communication, CNRS 


\title{
Huez-Alpe d'Huez, Brandes-en- Oisans
}

\author{
Marie-Christine Bailly-Maître
}

Identifiant de l'opération archéologique : 10021

Date de l'opération : 2009 (SD)

1 Le site de Brandes fait l'objet d'une fouille archéologique depuis 1977. La CIRA Centre-Est a souhaité que l'année 2009 soit consacrée à la préparation d'un bilan des quinze dernières campagnes de fouille et d'étude de ce site.

2 De 1995 à 2005, l'essentiel du travail a porté sur « L'eau et ses usages dans une entreprise minière médiévale ». Ce qui a conduit à s'intéresser aux vestiges situés à l'extrémité occidentale de l'agglomération. Là se concentre un ensemble d'indices à caractère industriel : l'aboutissement de la vaste canalisation C1 sur laquelle tournaient les meules à minerai, trois terrasses - B102 - qui portent des structures liées au lavage du minerai et à partir de 2006, les terrasses qui bordent la rive occidentale de la source Font Morelle ont fait l'objet d'une fouille qui n'est pas achevée. Au total, 33 bassins de lavage ont été mis au jour, certains ont fait l'objet d'une étude sédimentologique car tous étaient abandonnés, comblés de sables de gangue, plus rarement de pierres. Ce qui constitue un corpus totalement unique. L'ensemble du réseau des canalisations a été revu, de façon à mieux en détreminer la chronologie relative et le fonctionnement. Merci à Arnaud, Isabelle, Najlà, Camille et à tous ceux qui ont contribué à cette synthèse.

3 L'année 2009 a également permis de réaliser l'étude, par Nicolas Minvielle, de l'ensemble $\mathrm{du}$ corpus des meules à minerais, entières ou en fragments (plus de 200 individus). Les résultats ont été présentés à Rome, fin 2009, à l'occasion d'un colloque international sur les meules, ce qui a permis de nouer des contacts avec d'autres chercheurs qui seront utiles à l'avenir.

4 La réflexion a donc porté sur l'ensemble de la châne opératoire de l'enrichissement du minerai, depuis son « cassage » sur le carreau de la mine jusqu'au lavage, étape ultime de 
la minéralurgie. Les fouilles réalisées entre 1981 et 1986 sur le quartier occupant la rive orientale de la source ont été intégrées à cette synthèse.

Enfin, la documentation écrite a été entièrement revue par Fernand Peloux qui a ensuite élargi son champs d'investigations, afin de situer Brandes dans son territoire; dans un premier temps l'accent est mis sur les regest et compoix de la paroisse d'Huez, proche voisine de la paroisse de Brandes et qui l'a intégrée après la disparition de l'agglomération minière.

6 Une table ronde a été organisée, en juin 2009, afin de discuter, entre spécialistes, de l'état des connaissances sur ce site et de réfléchir à une nouvelle programmation centrée sur le village dans son territoire.

7 Bailly-Maître Marie-Christine, Gigante Arnaud, Warin Isabelle

INDEX

Thèmes : canalisation, mine, minerai

Index géographique : Rhône-Alpes, Isère (38), Huez

Index chronologique : Moyen Âge

operation Sondage (SD)

\section{AUTEUR}

MARIE-CHRISTINE BAILLY-MAîTRE

CNRS 